\title{
DERMOID CYST WITH ACUTE TORSION
}

\author{
Binita Kashyap1, Sanjay Patil2, Manisha Laddad ${ }^{3}$
}

${ }^{1}$ Resident, Department of Obstetrics and Gynaecology, Krishna Institute of Medical Sciences, Karad, Maharashtra, India. 2Professor, Department of Obstetrics and Gynaecology, Krishna Institute of Medical Sciences, Karad, Maharashtra, India. ${ }^{3}$ Associate Professor, Department of Obstetrics and Gynaecology, Krishna Institute of Medical Sciences, Karad, Maharashtra, India.

HOW TO CITE THIS ARTICLE: Kashyap B, Patil S, Laddad M. Dermoid cyst with acute torsion. J. Evolution Med. Dent. Sci. 2018;7(42): 4596-4598, DOI: $10.14260 /$ jemds/2018/1025

\section{PRESENTATION OF CASE}

Dermoid cyst is a cystic tumour that contains elements from all three germ cell layers, viz. the Ectoderm, the Endoderm and the Mesoderm. It is the most common germ cell tumour and also known as "Benign (Mature) Cystic Teratoma." Dermoid cyst accounts for $40 \%$ of all Ovarian Tumours in all ages, mostly young i.e. median 30 yrs. It is usually unilocular, but can be bilateral in $10-12 \%$ of cases. Torsion is present in $10 \%$ of cases and rupture and infection are also observed rarely.

A 45 years old married woman was admitted in emergency with pain in abdomen for 9 - 10 hours. Patient was conscious and well oriented. Her vitals were stable and UPT test was negative. Patient was posted for emergency exploratory laparotomy which proceeded to right dermoid cyst excision with abdominal panhysterectomy for right dermoid cyst with acute torsion. It was very rare presentation of dermoid cyst with acute torsion, which is visible in less than $10 \%$ of cases.

Dermoid cyst is the most common germ cell tumour and is also known as "Mature Cystic Teratoma." It contains elements from all the three germ cell layers, viz. the Ectoderm, the Endoderm and the Mesoderm. The term "dermoid" is a misnomer, since it is rarely composed only of skin (Ectoderm)-

- Monophyllum: When only one embryonic layer is present.

- Biphyllum: When two embryonic layers are present.

- Triphyllum: When all three layers are present.

Dermoid cyst accounts for $40 \%$ of all ovarian tumours in all ages, mostly young (median $30 \mathrm{yrs}$.). It is usually unilocular, but can be bilocular in $10-12 \%$ of cases.1,2 Torsion is observed in $10 \%$ of cases, but rupture and infection can also be observed rarely. $2 \%$ of dermoid cysts undergo a secondary malignant change and the most common type is Invasive Squamous Cell Carcinoma.

45 years old married woman was admitted in emergency with pain in abdomen for 9 - 10 hours. Patient was conscious and well oriented.

'Financial or Other Competing Interest': None.

Submission 06-09-2018, Peer Review 30-09-2018,

Acceptance 06-10-2018, Published 15-10-2018.

Corresponding Author:

Dr. Binita Kashyap,

Room No. 33, IHR Hostel,

Krishna Institute of Medical Sciences,

Karad, Maharashtra

India.

E-mail: binita611@gmail.com

DOI: $10.14260 /$ jemds/2018/1025

\section{(c) (i) $(5)$}

On examination, it was found that the vitals of the patient were stable. Per abdomen findings presented soft, 16 weeks' size mass palpable in lower quadrant of abdomen, hard in consistency and mobile with tenderness in right iliac fossa. $\mathrm{P} / \mathrm{S}$ findings was non-significant, but on P/V 14 - 16 weeks' mass arising from pelvic with fullness on POD.

\section{DIFFERENTIAL DIAGNOSIS}

These findings presented a possibility of Dermoid Cyst or Query Complex Ovarian Cysts with intermittent torsion or detorsion phenomenon. It also presented a possibility of Endometriosis and Para Ovarian Cyst.

Exploratory lab was done which proceeded to abdominal panhysterectomy, because family was complete.

\section{CLINICAL DIAGNOSIS \\ USG Findings}

USG indicated a $11.5 * 10.7 * 7.3$ sized cystic lesion in pelvis closely abutting fundus, anterior wall of uterus and posterior superior wall of urinary bladder.

\section{Intraoperative Findings}

Intraoperatively mass was cystic in consistency, spherical in shape with size around $8 \times 8 \mathrm{~cm}$ and surface was smooth glistening with adhesion with right external iliac artery and torsion and necrosis completely. Left sided FT and ovary normal.

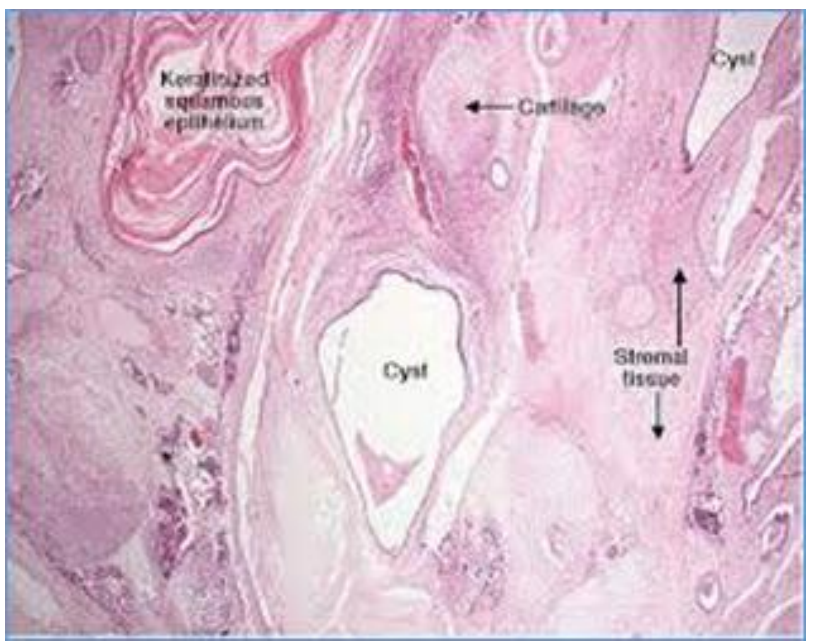

Figure 1. Dermoid Cyst: Most Common Germ Cell Tumour 


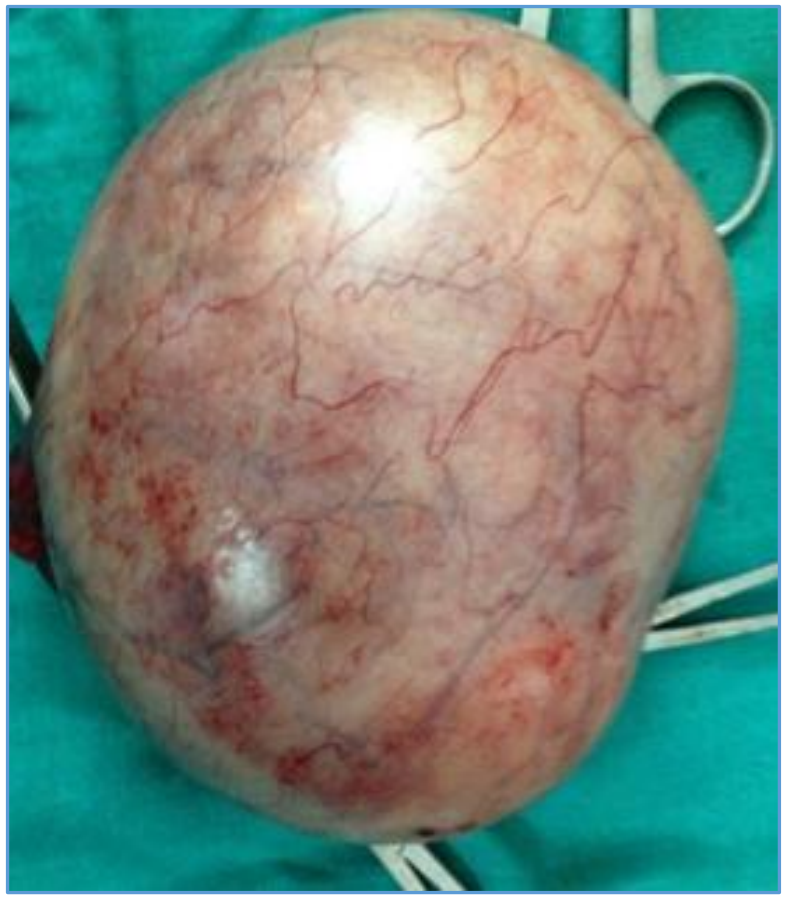

Figure 2. Large Ovarian Dermoid Cyst

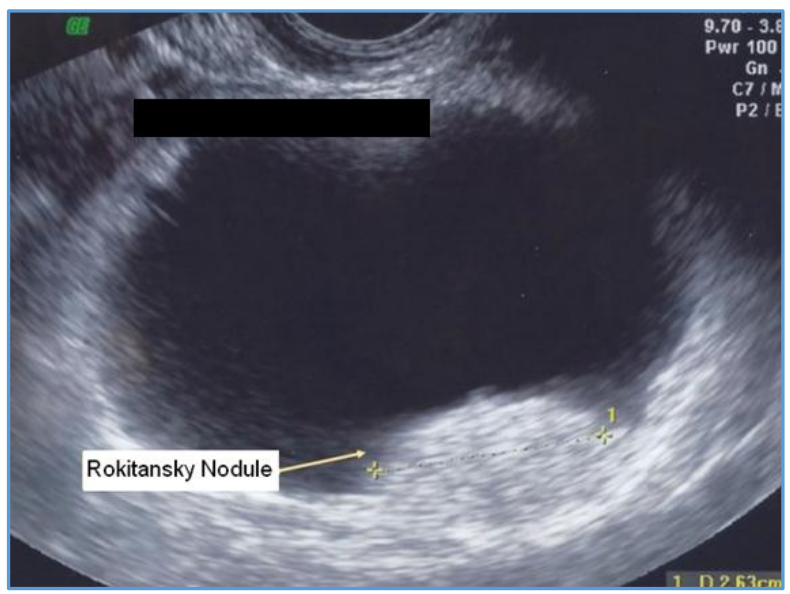

Figure 3. Rokitansky Nodule on the UGS Image

\section{PATHOLOGICAL DISCUSSION}

Dermoid cyst is usually asymptomatic in earlier stages and may give rise to lump in abdomen, pain, abnormal uterine bleeding and acute pain abdomen in case of torsion.

A doughy, non-tender, heavy mass is usually felt in anterior fornix (Kustner's Sign) ${ }^{3}$ should be suggestive of Dermoid Cyst.

Dallan's Sign: Visible indentation on the abdominal skin on pressing over the tumour is suggestive of Cystic Teratoma. ${ }^{4}$

On USG, characteristic finding is highly reflective dermoid plug (Rokitansky Nodule) that usually forms an acute angle with wall of the cyst and can produce acoustic shadowing due to presence of hair, calcium and bone. ${ }^{5}$

MR and CT will increase the diagnostic accuracy, because of their high sensitivity for fat and calcium content.

\section{DISCUSSION OF MANAGEMENT}

The cystic component of dermoid, sebum and hair may erode through the epidermal lining and elicit an inflammatory reaction and result in destruction of the wall of the cyst with progressive dissection by the cyst content.
Dissection may eventually extend deep into pelvic soft tissues or to the peritoneal surfaces. This is the mechanism that result in spontaneous rupture of large cystic teratoma.

Treatment is removal of dermoid cyst and the closure of the residual ovary. Usually, it can be shelled out of the ovary if preservation of fertility is an important consideration. Laparoscopic treatment of benign cystic teratoma has also been recommended, i.e. Laparoscopic Ovarian Cystectomy. ${ }^{6}$

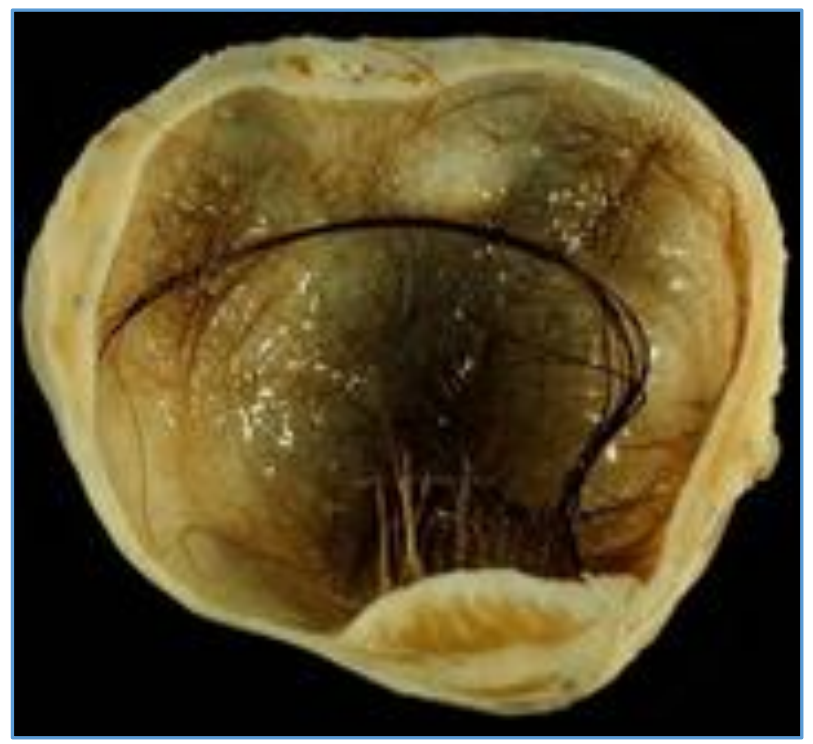

Figure 4. Dermoid Cyst consisting of Hair

\section{FINAL DIAGNOSIS}

During the excision of cyst, the right external iliac was partially avulsed, which lead to retroperitoneal haematoma on right side. Right ex. iliac artery sutured with Vicryl 2-0 and retroperitoneal haematoma fixed with stay suture and haemostasis confirmed. For this post-op, 3 PCV and 2 FFP was administered. On cut section of cyst having hairy tufts with sebaceous material present, which confirmed the diagnosis partially, but HPR confirmed the diagnosis conclusively stating "Mature Cystic Teratoma with haemorrhagic infarct of right ovary."

\section{ACKNOWLEDGEMENT}

Authors would like to acknowledge the help and guidance of Dr. Ashutosh Bahulekar who was the operating surgeon for the case. Authors would also like to thank all colleagues and staff members of Department of Obstetrics and Gynaecology, Krishna Institute of Medical Sciences for their support.

\section{REFERENCES}

[1] Pepe F, Lo Monaco S, Rapisarda F, et al. An unusual case of multiple and bilateral ovarian dermoid cysts. Case report. G Chir 2014;35(3-4):75-7.

[2] Comerci JT Jr, Licciardi F, Berghi PA, et al. Mature cystic teratoma: a clinicopathologic evaluation of 517 cases and review of the literature. Obstet Gynecol 1994;84(1):22-8.

[3] Krapp M, Baschat AA, Hankeln M, et al. Korrelation zwischen sonographischen und klinischen befunden in der plazentarperiode - Lösungszeiten, lösungszeichen und lösungsmodus. Geburtshilfe und Frauenheilkunde. 2001;61(7):507-10. 
[4] McLennan MK, Margolis M. Radiology rounds. Ovarian cystic teratoma (ovarian dermoid). Canadian Family Physician 1994;40:1717-24.

[5] Danish RB, Manchanda R, Deora S, et al. Dermoid cyst mimics retained surgical gauze (Gossypiboma). International Journal of Scientific Research 2018;7(2):310-12.
[6] Mais V, Guerriero S, Ajossa S, et al. Transvaginal ultrasonography in the diagnosis of cystic teratoma. Obstet Gynecol 1995;85(1):48-52. 